RESEARCH REPORT

\title{
Women brothel workers and occupational health risks
}

\author{
J Cwikel, K Ilan, B Chudakov
}

J Epidemiol Community Health 2003;57:809-815

See end of article for authors' affiliations ......................

Correspondence to: Professor J Cwikel, Ben Gurion University of the Negev, POB 653, Beer Sheva, 84105, Israel; jcwikel@bgumail.bgu.ac.il

Accepted for publication 3 April 2003

Study objectives: This study examined working conditions, reported morbidity, symptoms of posttraumatic stress disorder (PTSD) and depression and their relation to an index of occupational health risk among women working in brothels in Israel.

Design: Personal structured interviews with a scale of occupational risk that included seven self report items reflecting past and present morbidity and symptoms.

Participants and setting: A purposive sample of 55 women in three cities in Israel, between the ages of 18-38.

Main results: Most (82\%) women were trafficked into Israel to work illegally in prostitution, effectively deriving them of access to discretionary health care. A third of the sample $(32 \%)$ had a high score (between 3 to 6 ) on the index of occupational risk factors. A high score was not related to recent physician or gynaecological visits and was more common among illegal workers than those with residence status. A set of regression analyses showed that the most significant predictors of reporting a high level of occupational risk symptoms were starting sex work at an early age, the number of hours worked in a day, a history of suicide attempts and PTSD symptoms.

Conclusions: High occupational risk was found to be unrelated to recent physician or gynaecological visits, indicating that these visits were most probably controlled by the brothel owners and not by medical need as perceived by the women themselves. Furthermore, occupational risk factors were associated with some of the working and background conditions reported by women brothel workers. There is an urgent need for medical care for this high risk group.

$\mathrm{T}$ he nature of the sex industry in Israel has changed over the past decade, from one dominated by local prostitutes $^{12}$ to a business of much higher client volume where many non-Israeli women are working, ${ }^{3}$ although the exact number is impossible to calculate. ${ }^{1}$ Estimates based on police reports of the total number of women currently working in the sex trade indicate that in 1997 there were around $10000,{ }^{4}$ and recent police reports suggest that between 1000 to 3000 women, originally from countries of the former Soviet Union (FSU) are trafficked over the borders to work in prostitution in Israel each year. ${ }^{5}$ The United Nations Protocol defines trafficking as the transfer of persons from country to country to work in prostitution using threats, deception, and abuse of power such as withholding payments or benefits. ${ }^{6}$

In May 2000, Amnesty International cited Israel as a destination country for women trafficked to work in prostitution and this resulted in public debates about how to develop effective enforcement to combat trafficking and what services were needed to meet the needs of this population. ${ }^{7}$ Recently, the United States State Department issued a report including Israel in the "Third Tier" list of 23 countries where trafficking in women is endemic. ${ }^{8}$ Without current data on the circumstances of the women currently working in prostitution, it is difficult to develop an effective public policy response.

This social epidemiological, exploratory study was undertaken in order to begin to outline the nature of the health and safety risks that face women working in the sex industry of Israel today. Israeli health and social policy professionals are hampered by the lack of current data required to suggest means to deal with the health and the civil rights' needs of this population. This study describes the social context of health risk of these workers with a focus on self report measures that might be indicative of occupational health hazards. The objectives were to describe (1) the demographic profile of women currently working as prostitutes in brothels
(2) their self reported morbidity (3) to develop a parsimonious list of questions that were indicative of occupationally related health problems and (4) to assess the relation between occupational morbidity and other aspects of sex work and health behaviours.

\section{METHODS}

\section{Study population and procedures}

In October 2000, a research group was established to examine the health and working conditions of prostitutes working in Israel, with an emphasis on both mental and physical health. This group included experts on women's health, mental health, psychiatry, and gynaecology. Between the months of November 2000 to May 2001, phone numbers from sex service newspaper advertisements were contacted and the purpose of the study explained. Only a small number agreed to participate, but appointments led to some interviews for a fee through the brothel owner (6 of 55). With extensive fieldwork, we succeeded in gaining the confidence of several brothel owners in order to collect data from the prostitutes directly on a volunteer basis. As the contacts were made with women through the brothel owners, it is difficult to assess response rate. There were several instances where women declined the interview but the explanation was that there was a work schedule conflict. ${ }^{1}$ Interviews were conducted in three Israeli cities to create a purposive sample: Tel Aviv, Beer Sheva, and Eilat. This sample of 55 represents women working in brothels and does not include independent operators or street prostitutes who are likely to constitute a different demographic profile. Two interviewers conducted the interviews, at least one of whom was female, Russian

Abbreviations: PTSD, post-traumatic stress disorder; FSU, former Soviet Union 
speaking, and a psychiatrist. The questionnaire was an expanded version of the Farley questionnaire for sex workers with a validated Russian translation. ${ }^{9}$ Selected items relating to the demographic profile, working conditions, and presence of depression and post-traumtic stress disorder (PTSD) symptoms have been described previously, but will be presented here briefly to acquaint readers with characteristics of the sample. ${ }^{10}$

The questionnaire was a structured, closed instrument with some open-ended questions. The interviews were conducted out of hearing of any third parties and full anonymity was guaranteed. Oral consent was obtained after explaining the study (which was approved by our institutional review board). Each respondent was provided a list of agencies with Russian speaking staff that provided mental health, health services and legal advice. The average interview time was an hour and ten minutes (SD 0.19, range 30 minutes to two hours).

\section{Outcome measures}

Respondents were asked whether they had a diagnosed medical condition in the past five years from a list of 17 health problems (for example, high blood pressure, anaemia, asthma, tuberculosis). In addition, they were asked about the presence of pain and numbness in areas of their body (for example, the pelvic region, vagina, hands, mouth, back) that are likely to be areas of occupational strain in sex work. Additional measures of morbidity included self rated health (a 5 point scale, ranging from excellent to poor), whether they had any present health problems (yes, no), and when was the last time they had visited a physician, a gynaecologist and when they had last had an HIV test (three different questions).

PTSD symptoms were measured using the PTSD checklist (PCL) 17-item scale. ${ }^{11}$ The questions were asked about symptoms in the past month using a 5 point severity scale. Items were summed and a probable diagnostic cut off was set at those who scored over 50 as suggested by Weathers. ${ }^{11}$ Internal consistency as expressed by Cronbach's $\alpha$ was 0.90 . Depression was measured with six questions derived from the CES-D depression scale. ${ }^{12}$ Questions were asked about feelings associated with depressive mood in the past week using a 4 point scale. We used the probable diagnostic cut off point suggested by Sherbourne et al. ${ }^{13}$ Cronbach's $\alpha$ coefficient was 0.77 .

A scale of seven items that reflect risk factors that might put a sex worker at occupational risk was constructed based on face validity and symptoms that are frequently presented in self referrals to medical care ${ }^{14}$ reported in international research on health conditions of prostitutes, ${ }^{9}$ or have been suggested by occupational reviews of sex workers' health problems. ${ }^{15}$ These included positive answers to having had diagnosed in the past five years: repeated urinary tract infections, gynaecological problems, or sexually transmitted diseases (STDs) and current pain or numbness in the pelvic region or vagina. Pain or lack of feeling can increase the risk that tissues may be damaged during work and thus increase the likelihood of infection. Research among sexually active women have suggested that infections may be present but not reported unless a health care provider specifically asks about them. ${ }^{16}{ }^{17}$ The scale of seven items had adequate internal consistency (Cronbach's $\alpha=0.69$ ).

Two other scales were constructed reflecting traumatic or violent events that occurred before age 18 and those traumatic events that occurred while working in prostitution. The first scale had six items and included sexual abuse, physical abuse, rape, parental neglect, food deprivation, and homelessness (Cronbach's $\alpha=0.89$ ). The scale of violence at work had four items: being threatened with violence, being threatened with a gun, and being physically or sexually assaulted at work (Cronbach's $\alpha=0.71$ ).

Data were entered and analysed using SPSS-PC. Pearson's correlation coefficients were used to measure association between variables measured on ordinal or continuous scales. Measures of association between categorical variables were calculated by odds ratios. Odds ratios were calculated using EpiInfo.

The associations with legal status (citizen or new immigrant compared with illegal) were analysed by a separate set of correlations and $t$ tests to identify what might differ between these two groups. In an effort to delineate which risk factors were more important in predicting occupational risk, a series of exploratory multiple regressions were run to select the most important predictors from background variables, work related variables, and mental health status variables. These were conducted in groups of up to five independent variables to ensure adequate statistical power. Categorical variables such as legal status were included as dummy variables $(0,1)$.

Table 1 Demographic characteristics and sex work background and experience $(n=55)$

\begin{tabular}{|c|c|}
\hline \multicolumn{2}{|l|}{ Sample characteristics } \\
\hline \multicolumn{2}{|l|}{ Demographic characteristics } \\
\hline Age (years; mean (SD)) & $22.8(4.4)$ \\
\hline Range & $18-38$ \\
\hline Median & 22 \\
\hline Years of education, mean (SD) & 11.3 years $(1.6)$ \\
\hline Range & $9-15$ years \\
\hline Median & 11 \\
\hline \multicolumn{2}{|l|}{ Country of origin (\%) } \\
\hline Moldavia & 46.4 \\
\hline Ukraine & 25 \\
\hline Russia & 12.5 \\
\hline Asian Republics of FSU & 12.5 \\
\hline Brazil & 1.8 \\
\hline Israel & 1.8 \\
\hline \multicolumn{2}{|l|}{ Marital status (\%) } \\
\hline Married & 25 \\
\hline Never married & 13 \\
\hline Divorced or widowed & 30 \\
\hline Single with a steady partner & 32 \\
\hline \multicolumn{2}{|l|}{ Number of children (\%) } \\
\hline No children & 66 \\
\hline One child & 27 \\
\hline Two or three children & 7 \\
\hline \multicolumn{2}{|l|}{ Sex work experience and conditions } \\
\hline Age at first sex work (mean (SD)) & $20.9(4.2)$ \\
\hline Range & $16-35$ \\
\hline Median & 20 \\
\hline Years of work in prostitution (mean (SD)) & $2.1(1.9)$ \\
\hline Range & $\begin{array}{l}\text { One month to } \\
10 \text { years }\end{array}$ \\
\hline Median & 1 year \\
\hline Number of work hours per day (mean (SD)) & $11.7(3.9)$ \\
\hline Range & $4-18$ \\
\hline Median & 11.5 \\
\hline Number of clients per day (mean (SD)) & $11.6(6.1)$ \\
\hline Range & $4-25$ \\
\hline Median & 10 \\
\hline Number of days of work per week (mean (SD)) & $6.37(1.0)$ \\
\hline Range & $3.5-7$ \\
\hline Median & 7.0 \\
\hline Working 7 days a week (\%) & 68.5 \\
\hline Months since last visit to GP (mean (SD)) & $10.2(18.4)$ \\
\hline Range & $\begin{array}{l}\text { One month to } \\
6 \text { years }\end{array}$ \\
\hline $\begin{array}{l}\text { Months since last visit to gynaecologist } \\
\text { (mean (SD)) }\end{array}$ & $3.7(7.0)$ \\
\hline Range & $\begin{array}{l}\text { One month to } \\
4 \text { years }\end{array}$ \\
\hline Months since last HIV test* & $5.2(11.4)$ \\
\hline Range & Never to 6 years \\
\hline
\end{tabular}

*Excluding four respondents who never had HIV tests. 


\section{RESULTS}

Table 1 summarises the demographic profile and reported working conditions. The bulk of the women were young, with the majority under age 25 . The vast majority of respondents were women who had originated in republics in the FSU, particularly Moldavia and the Ukraine where economic conditions are reported to be the most severe. Only one native born Israeli was found. A small portion had either citizenship or new immigrant status (18\%). We asked the illegal residents about their method of entry into the country. The most common method reported was being smuggled by land over the border with Egypt (47\%). Others arrived by sea from Cyprus (13\%) or through Ben Gurion airport $(20 \%)$. Twenty per cent refused to say how they arrived.

One third $(34 \%)$ of the respondents had children and they supported them economically. Most $(78 \%)$ reported the ability to send $\$ 1285$ on average per month ( $\$ 1000$ was the modal sum with range of $\$ 125$ to $\$ 3000$ ) back to family in their country of origin. Average educational attainment was 11 years including some with academic training and 68\% had been trained in another occupation before working in prostitution.

Most respondents indicated that they worked seven days a week, with an average of close to 12 hours work a day, generating an average number of hours worked per week of 74.5. Using a conservative working month of 26 days, we estimate that this sample saw over 200 clients a month on average and perhaps some saw more than 300 clients a month.

Despite the small numbers of legally resident respondents (10), $t$ tests of the means show that this group differed from the illegal group (45) (all these results are significant at $\mathrm{p}<0.01$ ). Those with legal resident status were older (age $28.5 \vee 21.6)$, had started working professionally as prostitutes when they were older (age $25 v 20$ ), and had worked longer in the profession (3.7 years $v 1.7$ years). They worked fewer hours in the day $(8.2 v 12.4)$ and fewer days in the week $(4.95$ $v$ 6.7). No respondent with legal status reported working during the menstrual cycle compared with $50 \%$ of illegal group.

A large portion of the full sample of respondents (57\%) reported they had worked in prostitution in another country before coming to Israel, and 19\% had worked in two or more countries before, most in the areas of the FSU or eastern Mediterranean. Countries included: Turkey (the most commonly cited country), Cyprus, Italy, Albania, Saudia Arabia, Romania, Germany, China, Korea, Hungary, Slovakia, Greece, Bulgaria, Russia, and the Czech Republic. Of those who worked overseas before coming to Israel, only $37 \%$ consistently used condoms abroad, $46 \%$ used them occasionally, and $17 \%$ did not use them at all.

Respondents were asked if they had ever been sold against their wishes, either in Israel or in any other country. Eighteen per cent reported being sold against their wishes to a brothel owner, 64\% were transferred with their consent to a different place of work, and $18 \%$ were neither sold nor transferred-all of those with legal resident status. The modal number of times for being sold was twice. Almost all women (89\%) reported engaging in sex work of their own volition and three quarters reported that they knew before leaving their country of origin that this was to be their occupation upon arrival. The remainder decided to work in prostitution once in Israel, having been unable to find other employment with sufficient income. Two said it was against their will and two said it was not their idea to work in prostitution. Many commented that while they knew in advance that they were coming to Israel to work in prostitution, they did not anticipate the difficult working conditions.

Only a minority of the women had possession of their passport $(40 \%)$. Of the remainder, $20 \%$ reported that the brothel owner was keeping their passport but they could retrieve it if they wanted, $25 \%$ reported they knew where it was but could not get access to it, and 15\% did not know where their passport was. Only those with legal residence (18\%) had any type of health insurance, the rest, were dependent on the brothel owner for access to health care for which they paid out of their pocket.

A third of the sample (33\%) complained of a current health problem. Of those who mentioned a current health problem, quite a few mentioned problems related to work, such as frequent stomach aches from not being able to eat regular meals because of the workload, or dry skin from too many showers between clients. Two women reported that a physician had told them that repeated abortions had caused sterility. The number of abortions was strongly related to age $(r=0.50)$ and the age at first sex work $(r=0.42)$ so that the older women were more likely to report a greater number of abortions. One was pregnant at the time of the interview.

The frequency that past morbidity or symptoms were reported is listed in table 2 for items in the Occupational Risk Scale and other past and work related trauma. Aside from these, other symptoms that were commonly reported were: anxiety or depression $(21 \%)$, past fractures $(21 \%)$, problems with vision $(21 \%)$, head injuries $(19 \%)$, dental problems (17\%), high $(15 \%)$ or low blood pressure $(4 \%)$. No cases of tuberculosis were reported. Other symptoms reported included pain in the back $(42 \%)$, breast $(27 \%)$, hand $(25 \%)$, mouth $(15 \%)$, numbness in the hands $(17 \%)$, and numbness in the back $(19 \%)$. One fifth $(21 \%)$ of the sample was currently taking some type of medication prescribed by a physician (excluding oral contraceptives).

Of the sample, $27 \%$ had no occupational risk factors, $20 \%$ had one, $21 \%$ had two, $21 \%$ had three to four, and $11 \%$ had five to six risk factors. Those with legal status were less likely to have symptoms of occupational risk ( $1.0 \vee 2.18$ symptoms on average, $\mathrm{p}=0.05$ ).

The Occupational Risk Scale was linearly associated with self rated health so that the mean number of symptoms for those reporting their health as excellent, good, fair to poor increased from $1.2,1.3$ to $2.8(F=6.5, \mathrm{p}=0.003)$. The recency of doctor or gynaecological visits was not related to either the Occupational Risk Scale $(r=0.01, r=-0.09$,

Table 2 Variables in risk and trauma scales

Variables in the Occupational Risk Scale:

$\%$ Reporting morbidity in the past five years:

(1) Repeated urinary tract infections

(2) Gynaecological problems

(3) Sexually transmitted diseases

Current symptoms \%:

(4) Vaginal pain

(5) Pelvic pain

(6) Vaginal numbing

(7) Pelvic numbing

Mean (SD)

Variables in past trauma scale (before age 18) (\%)

(1) Homeless

(2) Lack food

(3) Parents' neglect

(4) Sexual abuse

(5) Physical attacked

(6) Rape

Mean number of past traumas (SD)

Variables in exposure to violence since working in

prostitution scale (\%)

(1) Threatened

(2) Threatened with a gun

(3) Physically assaulted at work

(4) Sexually assaulted at work

Mean number of work traumas (SD) 27

43

11

49

35

31

27

$2.0(1.8)$

27

25

30

33

43

32

$1.9(2.1)$ 
respectively), nor reporting a current health problem $(r=0.13, r=-0.01)$.

Almost all of the respondents were smokers (96\%). About one quarter of the sample indicated that someone had said they had a problem with alcohol (24\%), 31.5\% had ever tried drugs (mostly marijuana), but only three admitted that they were currently using some type of recreational drug. Using the clinical cut off, ${ }^{11} 17 \%$ of the sample showed symptoms of PTSD, and $29 \%$ were likely to have clinical symptoms of depression using the Sherbourne et al recommended cut off. ${ }^{12}$ Forty one per cent reported ever having suicidal thoughts, and $18.5 \%$ tried to commit suicide at least once.

All respondents reported using condoms for vaginal sex with customers, but six stated that they would be willing to forgo condoms if offered a sufficient financial incentive and if the person looked clean. Condoms were inconsistently used with customers during oral sex or not at all. Among those who have a current partner, only 19\% consistently used condoms, $73 \%$ never did, and $8 \%$ did occasionally. Condom use was more consistent among the casual partners reported by $38 \%$ of the sample. Among these contacts, 57\% used condoms consistently, 33\% did not, and $10 \%$ did occasionally. Aside from using condoms, 55\% also used a contraceptive sponge, and $24 \%$ used the pill. The sponge was primarily used for sexual contact during menstruation, in addition to condoms.

The inter-correlations between study variables are shown in the correlation matrix in table 3. Among the demographic variables, age was positively related to educational level, the number of years in the profession, and highly interrelated with age at first sex work. Younger women were more likely to be working longer hours per day, and more days of the week, although not necessarily more clients a day. Those respondents who were younger and had fewer years of education were more likely to have had a traumatic history before age 18. Work conditions were significantly interrelated, so that age at first sex work (like age of respondent) was negatively associated with longer working hours, more working days in the week and greater likelihood of past trauma. Hours in the day and days of the week were highly correlated as well as the number of clients per day, but unrelated to the length of time employed in prostitution. Those working longer hours and more days in the week were more likely to have fair or poor self rated health. Past trauma was related to longer working hours per day and more days in the week. Trauma at work was correlated with the length of time working in prostitution and the volume of clients as expressed by hours, days, and number of clients per day. The more exposure a prostitute had to clients, the greater the likelihood that she reported work related violence. Symptoms of PTSD were positively associated with past and work related trauma, depression, and poor self rated health.

As reporting a current health problem was associated with an average of 2.6 symptoms in the Occupational Risk Scale (compared with an average of 1.8 for those without a current health problem, $(F=2.9, \mathrm{p}=0.09))$, a cut off of two and over was selected as indicative of the unmet need for health services and medical attention. Table 4 shows the odd ratios of selected variables with the Occupational Risk Scale, dichotomised to form a low risk group (0-1 symptoms $(47 \%))$ and a high risk group (2-6 symptoms (53\%)). Both PTSD and depression were calculated with the clinical cut off indicative of a probable case. Prior drug use, physical and sexual abuse including rape before the age of 18 , and reported suicide attempts increased the risk of occupational health problems. Work during the menstrual cycle and work abroad before arrival in Israel were both variables associated with higher occupational risk as well as fair or poor self rated health. A willingness to forego condoms if offered an

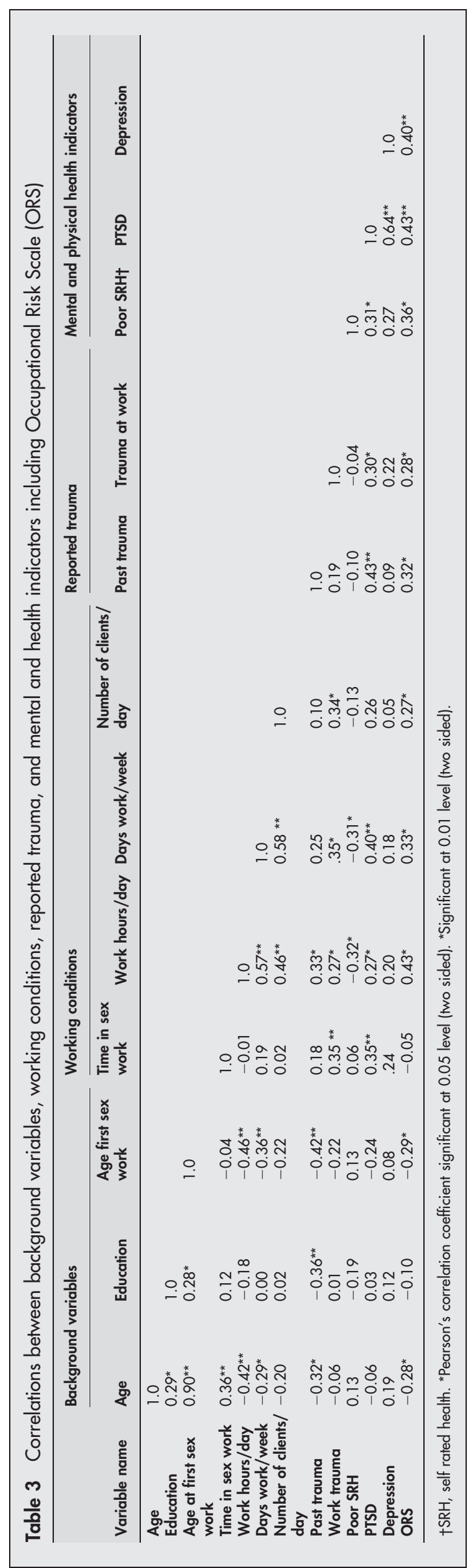


Table 4 Relation between working conditions, mental health indicators and Occupational Risk Scale

\begin{tabular}{|c|c|c|c|c|}
\hline $\begin{array}{l}\text { Background variablet } \\
\text { (\% in total sample) }\end{array}$ & $\begin{array}{l}\% \text { Among low risk } \\
\text { (0-1 symptoms) }\end{array}$ & $\begin{array}{l}\% \text { Among high risk } \\
\text { (2-6 symptoms) }\end{array}$ & Odds ratios & $\begin{array}{l}95 \% \text { Confidence } \\
\text { intervals }\end{array}$ \\
\hline Ever use drugs (31.5) & 12.5 & 46.7 & $6.13^{* *}$ & 1.31 to 32.56 \\
\hline Problem with alcohol (24.1) & 16.7 & 30.0 & 2.14 & 0.49 to 9.99 \\
\hline Sexual abuse before 18 (33.3) & 16.7 & 46.7 & $4.38 \dagger$ & 1.04 to 19.7 \\
\hline Physical abuse before 18 (42.6) & 16.7 & 63.3 & $8.64^{* \star *}$ & $2.03+\circ 40.05$ \\
\hline Rape before age 18 (32.7) & 12.5 & 50.0 & $7.0^{* *}$ & 1.47 to 37.86 \\
\hline Start sex work before 18 (37.5) & 23.1 & 46.7 & $3.11 \dagger$ & 0.84 to 11.88 \\
\hline $\begin{array}{l}\text { Work during menstrual period } \\
\text { (42.3) }\end{array}$ & 26.1 & 55.2 & $3.49^{*}$ & 0.93 tol3.64 \\
\hline $\begin{array}{l}\text { Willing to forego condom use at } \\
\text { work }\end{array}$ & & & & \\
\hline Occasionally (12.5) & 0.0 & 24.0 & $2.21^{*}$ & 1.58 to 3.08 \\
\hline Threatened at work (33.3) & 13.0 & 56.5 & $8.67^{* *}$ & 1.7 to 50.19 \\
\hline PTSD symptoms (17) & 9.1 & 29.2 & $3.89+$ & 0.61 to 31.4 \\
\hline Depressive symptoms (29) & 21.7 & 44.0 & 2.83 & 0.68 to 12.6 \\
\hline Suicidal thoughts (41) & 41.7 & 75.9 & 4.4 * & 1.3 to 14.3 \\
\hline Fair poor evaluation of health (44.6) & 23.1 & 63.3 & $5.76^{* *}$ & 1.55 to 22.46 \\
\hline Sex work abroad (57) & 33.3 & 76 & $6.3^{* *}$ & 1.48 to 28.99 \\
\hline
\end{tabular}

†Only the percentages of the presence of risk factors are shown, as the second half of the table always is $100 \%-$ the value presented. $¥ O R$ approaches significance at $0.05<p<0.10$. ${ }^{*} O R$ significant at $p<0.05$. **OR significant at $\mathrm{p}<0.01$. ${ }^{* *} \mathrm{OR}$ significant at $\mathrm{p}<0.001$.

additional monetary incentive, while not common (6 of 48), was only reported among those with high risk. Legal status was not related to scores on depression, past trauma, work related trauma, or PTSD symptoms.

Results from the multiple regression showed that when background variables (age, educational level, resident status (dummy variable), number of children, and age at first professional sex work) were analysed by a step wise procedure to predict occupational health risk, only age at first sex work was retained $(\beta=-0.30, F=5.09, \mathrm{p}=0.028)$. In an analysis of past indicators of mental health problems, childhood trauma, number of abortions, had suicidal thoughts, ever use drugs, have a problem with alcohol (last three dummy variables), only suicidal thoughts were retained in a step wise procedure $(\beta=0.37, F=7.4, p=0.009)$. In a regression with working conditions including the number of days in a work week, the number of hours in a work day, exposure to violence at work, working during menstrual cycle, working abroad before now (last two dummy variables), only the number of work hours was retained in a stepwise analysis $(\beta=0.44, F=10.5, p=0.002)$. In an analysis of current mental health symptoms, PTSD symptoms and depression, PTSD was retained $(\beta=0.43, F=10.0$, $\mathrm{p}=0.003$ ). In a final regression analysis that included all the variables that were retained in the separate analyses, two variables: PTSD variables and the number of work hours were retained in a stepwise analysis predicting the occupational risk scale. The adjusted $\mathrm{R}^{2}$ was 0.23 for this final regression.

\section{DISCUSSION}

This constitutes the first study of self reported morbidity of women working in brothels in Israel in recent years when most of those working have been trafficked into the country and are working without access to basic civil rights such as health care. ${ }^{6}$ The fact that there is no relation between recent doctor or gynaecological visits and reported symptoms further indicates that gynaecological visits are demanded by the brothel owners but are not in response to current pain, discomfort or symptoms. The high number of interrelated variables in both the bivariate and multivariate analyses suggests that there are many pathways into the world of economically motivated sex work and that working illegally puts women at higher health risk. The significant association of indicators of PTSD with high levels of occupational

\section{Key points}

- Most women in the sample were trafficked and lacked access to discretionary health care services, the significant proportion of them reported being sold or transferred between brothel owners, and lacked access to their personal documents (passport)

- A set of questions about past health problems (repeated urinary tract infections, gynaecological problems and sexually transmitted diseases) and current pain and numbness in the pelvic and vaginal areas, was related to self rated health, symptoms of mental health problems, and past and present behaviours likely to increase health risks.

- These sex workers reported a very high number of clients per day and long working hours. These are working conditions that increase sex workers' occupational health risks. Furthermore, the longer the women work in this sector, the more likely they are to be exposed to violence at work. Women who had been trafficked into the country to work had much more difficult working conditions than those with visas or citizenship.

associated symptoms suggests that there are somatic indicators of current mental health distress.

The results in table 4 and from the regression analyses suggest that a cluster of symptoms and self report items about past and present health are associated with early traumatic events, current external events (experiencing violence while working) and behaviours (work abroad, working during menstrual cycle, willingness to forego condoms). These results deserve validation with additional data from other samples of sex workers, including both clinical measures of health and infection. This research team is in the process of replicating these findings with a sample of sex workers who are in prison awaiting deportation from Israel to their countries of origin, which mitigates the possible bias of access to respondents through brothel owners, but restricts the sample to those who are resident in Israel illegally. 


\section{Policy implications}

- Being trafficked to work in prostitution puts women at risk of compromised basic civil rights and increases their occupational health risk. There is an urgent need to reach out to this disenfranchised population, which in general lacks access to basic health services and may be exposed to health hazards through their work.

Epidemiological research has typically identified prostitutes as a population involved in transmitting STDs. ${ }^{18}$ This view may be overly simplistic, as among subgroups where condoms are used consistently with clients, the infection rate among prostitutes may be fairly low and associated primarily with personal sexual contacts with which condoms are less commonly used. ${ }^{19-22}$ For example, in a study in Copenhagen, prostitutes who were injecting drug users and working in the street were more likely to be infected with STDs than prostitutes working in other venues. ${ }^{19}$

It is also clear that prostitutes are not a single homogeneous group and some have personal characteristics and health behaviours that increase their risk for both STD infection and other health problems. In this sample, legal resident status was associated with slightly better health and with ability to access health care through health care insurance. Studies in other countries have indicated that foreign prostitutes have a significantly higher risk of being infected during sex work, in part because of their difficulties in negotiating consistent condom use among their clients. ${ }^{9}{ }^{18}$ For example, prostitutes of foreign origin who had also worked in another country before entry into Australia, were more likely to report inconsistent condom use and thus increase their risk of occupational sexually transmitted disease. ${ }^{20}$

Identifying and treating STD infection among women in prostitution is important not only for their health but also for the protection of their customers. However, the narrow focus only on STDs may obscure other health problems that are prevalent among women in the sex industry. Current studies take a more balanced approach to understanding the occupational risks and hazards affecting the health of women working in prostitution. ${ }^{15}{ }^{21-23}$ Also, some trafficked women work in prostitution for a period of time and then return to other occupations and their families in their home countries. Thus, health problems acquired during prostitution may affect their health and functioning in later years.

Other health problems commonly reported among women working as prostitutes include: high rates of injury from pimps and clients, ${ }^{18} 192324$ current untreated health problems, high rates of drug and alcohol use, PTSD, and depression..$^{22-25}$ Past childhood trauma or neglect may increase the likelihood of working in prostitution, being infected by STDs and having PTSD symptoms. ${ }^{96}$

We did find that women were working very long hours and with a very high volume of customers. By comparison other studies have found that women were seeing an average of 82 $\left(\right.$ Nevada $\left.^{27}\right), 95$ (S Africa $\left.{ }^{28}\right)$, and 115 clients (Netherlands ${ }^{29}$ ) per month. In a study of women working as prostitutes in a truck stop in South Africa, women took time off during their menstrual cycle as a break from work. ${ }^{28}$ If these reports are valid, then the women in this study are seeing at least twice the number of clients per month than is common in other parts of the world. Furthermore, the greater the number of contacts, the more likely they were to encounter work related violence and symptoms indicative of occupational risk.

The findings show that only a portion of the women working in prostitution come from a background that includes parental neglect, abuse and sexual abuse, and report using drugs in the past. This contrasts with other studies that report a much higher rate of past trauma and drug use among women who are street prostitutes. ${ }^{93}$ A history of past trauma increased the risk of beginning work in prostitution at a young age and continuing to show symptoms of PTSD. While both past and work related trauma increased the likelihood of PTSD, past trauma was not necessarily associated with reporting more work related trauma. Past drug use was associated both with greater occupational risk, while the lack of current drug use was explained as a policy imposed by the brothel owners.

There are some caveats that should be mentioned. It was not possible to randomly sample women who were working illegally, as we required the cooperation of the brothel owners to obtain interviews. We therefore may have been seeing women working in relatively better conditions than in those places where brothel owners would not permit access to outsiders. Thus, for example, women reported that they had had recent HIV testing at the initiative of the brothel owners. However, with problematic access to these illegal sex workers, we were unable to conduct independent clinical examinations to verify the reported morbidity or STD status.

While the sample was a selection of brothel workers and not necessarily representative of all those working in the Israeli sex industry, the results are still indicative of factors associated with a high risk for occupational health problems. The questions used to form the index of occupational risk may be a useful tool in identifying women who are in need of health services. The proportions of those who currently report symptoms and yet are not being treated indicate the need to have health services accessible to these women, regardless of their civilian status. Recently the Israeli Ministry of Health established a first sexually transmitted disease clinic that is open to persons on an anonymous basis. This is a welcome first step to improving the access to health care of this population.

\section{ACKNOWLEDGEMENTS}

The authors would like to thank Drs Vladmir Rudman, Moshe Golan, Alex Kaftzan, Irina Kaufman, and Igor Libov for their help with field interviews. The research team would also like to acknowledge the cooperation of anonymous brothel owners who facilitated access to their workers. The research protocol received approval of the Institutional Review Board of Soroka University Medical Center and the respondents provided oral informed consent at the onset of the interview.

\section{Authors' affiliations}

J Cwikel, K Ilan, Center for Women's Health Studies and Promotion and Department of Social Work

B Chudakov, Faculty of Health Sciences, Ben Gurion University of the Negev, Beer Sheva, Israel

\section{REFERENCES}

1 Hazani M. Deviant companionship and interaction across an intergroup "seam": Arab pimps and Jewish prostitutes. Plural Societies 1989;19:55-72.

2 Shoham G, Rahav G, Markovski R, et al. Family variables and stigma among prostitutes in Israel. Journal of Social Psychology 1983;120:57-62,

3 Vanderberg M. Trafficking of women to Israel and forced prostitution. [In Hebrew]. Jerusalem, Israel: Israel Women's Network, 1997.

4 Katzir D. Trafficking in women from countries of the former Soviet Union to Israel. [In Hebrew]. Jerusalem: The Israeli Knesset-Research and Information Center, 2001.

5 Tzimuki T, Ben-David A. The price per woman: up to 10,000 shekels. Yediot Aharonot 26 Nov 2002.

6 United Nations. United Nations protocol to prevent, suppress and punish trafficking in persons, especially women and children. Office of Drug Control and Crime Prevention, United Nations http://www.undcp.org/odccp/ trafficking_human_beings.html, 2002;(accessed 28 November 2002).

7 Amnesty International Israel. Human rights abuses of women. London: Amnesty International, 2000.

8 Algazy J. Trafficking in women could threaten US aid. Tel Aviv, Israel: Ha'aretz, 2001. 
9 Farley M, Barkan H. Prostitution, violence, and posttraumatic stress disorder. [Russian translation by Dr Svetlana llina]. Women Health 1998;27:37-49.

10 Chudakov B, Ilan K, Belmaker RH, et al. The motivation and mental health of sex workers. Journal of Sexual and Marital Therapy 2000;28:305-15.

11 Weathers FW, Litz BT, Huska JA, et al. PLC-C for DSM-IV. Boston: National Center for PTSD-Behavioral Sciences Division, 1994.

12 Radloff L. The CES-D scale: a self-report depression scale for research in the general population. Applied Psychological Measurement 1977;1:385-401.

13 Sherbourne CD, Dwight-Johnson M, Klap R. Psychological distress, unmet need, and barriers to mental health care for women. Women's Health Issues 2001; 11:231-43

14 Carr SV. The health of women working in the sex industry-a moral and ethical perspective. Sexual and Marital Therapy 1995;10:201-13.

15 Alexander P. Sex work and health: a question of safety in the workplace. J Am Med Womens Assoc 1998:53:77-82.

16 Horgan M, Bersoff-Matcha S. Sexually transmitted diseases and HIV: a female perspective. Dermatol Clin 1998;16:847-51, xv-xvi.

17 Sturm AW, Wilkison D, Ndovela N, et al. Pregnant women as a reservoir of undetected sexually transmitted disease in rural South Africa: implications for disease control. Am J Public Health 1998;88:1243-5.

18 Day SW, Ward H. Sex workers and the control of sexually transmitted diseases. Genitourin Med 1997;73:161-8.

19 Alary M, Worm AM, Kvinesdal B. Risk behaviors for HIV infection and sexually transmitted diseases among female sex workers from Copenhagen. Int J STD AIDS 1994;5:365-7.
20 O'Connor CC, Berry G, Rohrsheim R, et al. Sexual health and use of condoms among local and international sex workers in Sydney. Genitourin Med 1996;72:47-51.

21 van Haastrecht HJ, Fennema JS, Coutinho RA, et al. HIV prevalence and risk behaviour among prostitutes and clients in Amsterdam: migrants at increased risk for HIV infection. Genitourin Med 1993;69:251-6.

22 Ward H, Day S, Weber J. Risky business: health and safety in the sex industry. Sex Transms Infect 1999;75:340-3.

23 Weinberg MS, Shaver FM, Williams CJ. Gendered sex work in the San Francisco Tenderloin. Arch Sex Behav 1999:28:503-21.

24 Church S, Henderson M, Barnard M, et al. Violence by clients toward female prostitutes in different work settings: questionnaire survey. BMJ 2001;322:524-5.

25 Valera RJ, Sawyer RG, Schiraldi GR. Perceived health needs of inner-city street prostitutes: a preliminary study. Am J Health Behav 2001;25:50-9.

26 Zierler S, Feingold L, Laufer D, et al. Adult survivors of childhood sexual abuse and subsequent risk of HIV infection. Am J Public Health 1991;5:572-5.

27 Albert AE, Warner DL, Hatcher RA. Facilitating condom use with clients during commercial sex in Nevada's legal brothels. Am J Public Health 1998;88:643-6.

28 Karim QA, Karim SSA, Soldan K, et al. Reducing the risk of HIV infection among South African sex workers: socioeconomic and gender barriers. Am J Public Health 1995:85:1521-5.

29 Hooykaas C, van der Pligt J, van Doornum GJ, et al. Heterosexuals at risk for HIV: differences between private and commercial partners in sexual behavior and condom use. AIDS 1989;3:525-32. 